ECONOMIC GROWTH CENTER

YALE UNIVERSITY

P.O. Box 208629

New Haven, CT 06520-8269

http://www.econ.yale.edu/ egcenter/

CENTER DISCUSSION PAPER NO. 953

\title{
Fertility in Developing Countries
}

\author{
T. Paul Schultz \\ Yale University
}

May 2007

Notes: Center discussion papers are preliminary materials circulated to stimulate discussion and critical comments

Support from the Rockefeller Foundation for the training and research program on the family in low income countries at Yale University is acknowledged. Forthcoming in "A Dictionary of Economics," $2^{\text {nd }}$ Edition: Palgrave.

This paper can be downloaded without charge from the Social Science Research Network electronic library at: $\underline{\text { http://ssrn.com/abstract }=985363}$

An index to papers in the Economic Growth Center Discussion Paper Series is located at: http://www.econ.yale.edu/ egcenter/research.htm 


\title{
FERTILITY IN DEVELOPING COUNTRIES
}

T. Paul Schultz

\begin{abstract}
$\underline{\text { Abstract }}$
The associations between fertility and outcomes in the family and society have been treated as causal, but this is inaccurate if fertility is a choice coordinated by families with other life-cycle decisions, including labour supply of mothers and children, child human capital, and savings. Estimating how exogenous changes in fertility that are uncorrelated with preferences or constraints affect others depends on our specifying a valid instrumental variable for fertility. Twins have served as such an instrument and confirm that the cross-effects of fertility estimated on the basis of this instrument are smaller in absolute value than their associations.
\end{abstract}

Keywords: $\quad$ Fertility Determination, Malthus, Household Demands, Fertility Effects

JEL Codes: D13, J13, N30, O15 
Fertility is a choice by parents involving a life-cycle claim on their resources, from which they may receive satisfaction as consumers and benefit as producers from children's labour and caregiving support. In addition, fertility may be the source of externalities that affect members of society other than the decision-making parents, in which case society may view fertility as a legitimate issue for social policy. To forecast fertility and the conditions under which public policies might be justified to modify fertility, economists require a basic understanding of its determinants as well as social consequences. In approaching this topic from the perspective of low-income countries today, the ideas of Malthus remain influential. He argued that population growth caused by high fertility erodes the welfare and productivity of workers, and thus social policy which fostered greater fertility, such as the English Poor Law, contributed to 'overpopulation'. Before considering how these spillover effects of fertility might be identified, an overview of historical thinking about the demographic-economic system may help to indicate the context in which Malthus’s thinking was relevant to pre-industrial Europe, and how modern economics has extended his thinking to fertility as a lifetime choice of parents related to their time allocation and accumulation of human and physical capital.

\section{Malthus' framework for the pre-industrial demographic-economic equilibrium}

The determinants of fertility have engaged the interest of economists for some time. Adam Smith (1776) noted families were larger in settings where labour was scarce and child labour was especially valuable to parents, as in North America with its abundant land. Smith recognized that child mortality was higher among the poor, especially among those who were dependent on charity (for example, the Poor Laws). However, Malthus (1798) viewed fertility not as an individual choice but as an outcome of social institutions, because he did not think birth control was effective. He thought fertility was governed by the economic requirements society placed on a couple before allowing them to marry. Once married, the 'constant passion of the sexes' would lead in unregulated fashion to fertility. Society therefore restricted entry into marriage to those with favourable prospects for a livelihood or the income and assets to support the children that were expected to follow from the union. Over his lifetime, Malthus accumulated corroborating evidence on fertility, population growth and economic growth. Historians have since added to Malthus's evidence, confirming that Europe exhibited a late median age at marriage for a woman in her mid-twenties. This delay in childbearing led European women to have four or five births 
over their lifetime, rather than the six or seven if they had married five years earlier. Given the short life expectancy in pre-industrial Europe of about 35-40 years, this restrained level of fertility diminished substantially the resulting rate of population growth, except at frontiers of settlement where labour was scarce, land abundant, and marriage consequently early.

Heckscher (1963) thought Malthus’s framework was relevant to Sweden. With the Swedish church's good records of marriages, births and deaths, and the Swedish king's need to estimate crop yields (for the purposes of taxation), annual time series for Sweden after 1720 appear accurate and show a positive covariation in marriage and fertility with good crop years, and shortfalls in marriage and subsequently fertility following poor crop years. Temperature and rainfall data available for Sweden after 1750 allow later analysts to incorporate this exogenous variation in weather and employ vector autoregression to estimate weather-driven Malthusian cycles in wages, fertility, as well as mortality (Eckstein, Schultz and Wolpin, 1984).

Working with French and Swiss parish registries of marriage, births, and deaths, Louis Henry (1972), the demographer, found evidence that couples exhibited a 'natural' rate of childbearing after marriage, until they eventually began to increase the intervals between their births after later parities, if economic conditions became less favourable. The emergence of this form of parity-specific application of birth control over the life cycle of marriages was interpreted by Coale (1973) as an indicator of the onset of the 'demographic transition', when cultural restraints on fertility evolved from 'natural' proximate determinants to controlled 'modern' reproductive behaviour relying primarily on birth control.

Parish registries were then sampled from England from 1541 to 1871 by Wrigley and Schofield (1981) to further investigate the Malthusian framework. Lee (1981) found that increases in marriage and birth rates were related to good weather and resulting declines in the price of wheat, as Malthus would have expected. But only about half of the covariation in weather/prices and annual birth rates is due to the fluctuations in first births that follow in the wake of variations in marriage. The other half is explained by variation in the length of inter-birth intervals. The latter finding casts doubt on Malthus's view that in this pre-industrial period couples did not exercise fertility choices within marriage. This spacing of births in response to economic wage cycles implied that the adoption of parity-specific birth control may not have been a cultural innovation, as assumed by Coale, but a customary form of individual behaviour adopted when additional births were unwanted. Some couples in pre-industrial societies appear 
able and willing to practice effective birth control when motivated economically. Fertility is thus to some degree a voluntary choice variable within marriage even in pre-industrial societies.

As the Industrial Revolution progressed in Europe and real wages increased, fertility nonetheless began to decline widely by the end of the 19th century. The Malthusian framework needed to be amended further to fit this experience in Europe and be applicable to low-income countries after 1960 as new methods of family planning were disseminated in the world and fertility fell despite modern economic growth. How was the secular decline in fertility to be explained in the face of rising personal incomes? The decline in child mortality, which gathered speed after 1870, reduced the need for parents to have extra births to replace the one out of five who might have at earlier times died from childhood diseases and infections. Parents might also scale back their demand for 'insurance' births motivated to reduce the likelihood that a couple would sustain above average child losses (Schultz, 1981). Becker (1960) proposed that the relative price of rearing children increased over time, causing the decline in parents' demand for children. Mincer (1963) hypothesized that an increase in women’s wages increased a couple’s opportunity cost of having children, raising the shadow price of children. He argued that the rise in female labour-force participation and the decline in fertility were both caused by conditions increasing women's wages relative to other consumer prices and men's wages. These empirical patterns in the United States were soon replicated in other high-income countries.

Changing the relative prices of outputs of the economy is one possible source of variation in women's wages relative to men's that could explain changes in fertility. Men's labour in European agriculture was critical for plowing and producing food grains, whereas women specialized in home production as domestic servants and wives and to some degree in animal husbandry and the production of dairy commodities. Consequently, changing scarcity of grains relative to livestock and dairy product contributed to swings in the relative wages of men and women in Europe. The secular decline in international grain prices relative to dairy and livestock prices in the latter half of the 19th century was unprecedented due to the opening of new lands at the frontiers of European settlement in the United States and Russia, and contributed along with changes in production technologies to the rise in women's agricultural wages relative to men's in northern Europe and to the decline in fertility. Swedish historical data by region document after 1860 the fall in world grain prices, the associated increase in the wages of women relative to men, and the secular fall in fertility, when other developments are controlled for (Schultz, 1985). 
Another factor credited with reducing fertility is the improvement in birth control technology, which reduced the monetary and psychic cost of limiting births, and provided techniques controlled by women, which were independent of sex. The major advances in technology occurred in the 1960s with the introduction of oral steroids (the pill) and the intrauterine device (IUD), followed by further refinements in their delivery systems. Traditional mechanisms for population control such as abortion, infanticide, coitus interruptus, and condoms have nonetheless allowed individuals to adjust their family size and affect population growth in various periods and parts of the world, well before the advent of these modern means of birth control. Although they may have facilitated the later demographic transition, these birth control technologies do not appear to have been necessary.

\section{Microeconomic models of fertility behaviour}

Willis (1973) adapted a comparative advantage trade model to the household lifetime fertility choice problem, wherein women's education was assumed to enhance women's productivity only in the market, and thereby increase the relative price of home production and decrease their demand for fertility. In his economic treatise on the family, Becker (1981) assigns a central role to market/non-market specialization of spouses in the household, with childbearing and rearing being the dominant non-market production activity traditionally performed by women.

To place more structure on fertility choices, Becker $(1960 ; 1981)$ and Willis (1973) hypothesize that parents viewed the human capital of their children (child quality) as a substitute for their number of children (child quantity). If this were the case, then by definition incomecompensated cross-price effects should be positive between child quantity and quality. In other words, increasing the price of children, for example by reducing the cost of birth control, would directly decrease fertility and indirectly increase the demand for child quality (with income held constant). Conversely, increasing the wage returns to schooling in the labour market would directly increase the demand for schooling and indirectly decrease the demand for births. Becker and Lewis (1974) postulate further that the income elasticity of demand for child quality exceeded the positive income elasticity for child quantity, which could account for the paradoxical decline in fertility with growth in income, without having to assume that children (quantity) are an 'inferior' good for which income effects are negative, or to show increases in women's value of their time in the modern economy caused the decline in their fertility. 
The decline in fertility by half in high-income countries during the 20th century brought population growth to a halt in many of these countries. The decline in fertility by more than half in low-income countries in 40 years (1965-2005) is not yet comprehensively accounted for, although demographers are agreed that these trends in fertility are irreversible and the size of the world's population will stabilize later in the 21st century. How much does each of these conceptually distinct factors economists have described explain of this remarkable decline in fertility? I do not yet find a consensus on how to weight these factors in explaining cohort fertility. What fraction is due to an exogenous decline in mortality, the decline in the relative

value of child labour, the increase in the value of women's time used in child care and the related increase in their empowerment, the increase in returns to schooling children, the greater income elasticities of demand for child quality than for quantity, and finally the improvements in birth control technology?

\section{Identifying the effect of fertility on the welfare of families and society}

The policy-relevant externalities of fertility could arise at the aggregate level or in terms of substitution effects within families. Malthus assumed that fertility added to subsequent generations of workers, which reduced their wages and also changed the age composition of the population. But empirical evidence for these aggregate effects of fertility has not led to a consensus on their importance for today's low-income countries (National Research Council, 1986). At the microeconomic level of the family, fertility is found to be closely associated with other life-cycle choices by parents, including the share of time women allocate to the market economy, the investments parents make in the human capital of each of their children, and perhaps the savings out of income they accumulate in physical capital, possibly for old age support or precautionary insurance. But to assess the magnitude of these cross-effects of fertility, researchers must first specify an exogenous factor (not a choice variable within the orbit of the family) that affects fertility but leaves other constraints on the family life-cycle choices and outcomes unaffected and is unrelated to parent preferences (Schultz, 2005). In other words, an exclusion restriction or a valid instrumental variable is needed to account for some part of the variation in fertility that is independent of parent preferences and family life-cycle economic constraints. Otherwise, these cross-effects observed at the family level may not be causal and cannot be expected to occur when population policies reduce (or increase) fertility. 
Twins are proposed by Rosenzweig and Wolpin (1980; 2000) as a 'shock' to the quantity of children that is uncorrelated with parent preferences or unobserved determinants of other family and child outcomes. Adjustment of investment in the schooling of other children in the family due to the occurrence of twins can then test the quantity-quality substitution hypothesis. They found support for the trade-off of quantity-quality on non-twin siblings in rural Indian households observed in 1970. A larger sample of twins collected in China provides the basis for estimating the impact of a twin on the quality of earlier- or later-born siblings, providing bounds to the magnitude of the cross effects, adjusted for substitution effects between siblings (Rosenzweig and Zhang, 2006). However, when twins are an instrument for fertility, the estimated quantity-quality trade-off tends to be smaller in absolute value than when estimated by direct association, that is, ordinary least squares (OLS). This could be due to the twin instrument being weak either because it occurs for only a small fraction of births (for example, one per cent) or because the underlying causal relationship is in fact weak and appears important only in biased single-equation associations (that is, OLS). The heterogeneity in parent preferences or other unobserved determinants of behavior could inversely affect child quantity and quality (Schultz, 2005).

Other studies have exploited twins as an instrument for fertility to assess how exogenous fertility affects the mother's market labour supply. These studies in high- and low-income countries generally confirm that the twin instrumental variable estimate of the effect of a birth on the mother's market labour supply tends to be absolutely smaller (negative) than the OLS estimate. The Durbin-Wu-Hausman specification test rejects the exogeneity of fertility in the determination of the mother's allocation of time to market work (Schultz, 2005), implying that the consistent instrumental variable estimate is preferred over the OLS estimate.

This twin-based cross effect of fertility on mothers’ labour supply may help to explain how policies which reduce fertility can facilitate modern economic growth, by adding to the per capita supply of labour and increasing the human capital of future generations. Finally, if parents when they have fewer children increase life-cycle savings for their support in old age, policies that facilitate a decline in fertility could raise savings and further augment growth rates. But estimates of these three potential cross effects of fertility-reducing population policies remain currently speculative.

The other instrument commonly used to identify the consequences of fertility on the 
welfare of families relies on the sex composition of births, and has serious drawbacks. This variable may significantly affect parents' decisions on whether to have further children, and it may be assumed to be approximately independent of parent preferences or family constraints if there is no sex-selective abortion or infanticide. But this variable may not satisfy the criteria for a valid instrument, because the social and economic consequences of a child's sex involve many culturally distinct costs and benefits for his or her parents, such as the provision of dowries for daughters in some parts of the world. Thus, the sex composition of early births is likely to involve lifetime wealth effects for parents, in addition to affecting fertility, giving rise to many changes in family time allocation, expenditure patterns, and life-cycle savings (Rose, 2000). Therefore, the sex composition of children is not an instrumental variable for estimating how parents respond to a change in their fertility due to a population policy, if income and other family constraints are held constant. Finally, it should be noted that population policies may on the one hand subsidize learning and use of birth control, or at the other extreme fix a birth quota, as in China. There is no reason to expect expanding voluntary choices in the first case will have the same effect as rationing choices in the other policy regime.

\section{Conclusions and research challenges}

Parents may altruistically internalize in their fertility decisions the effects of their fertility on their welfare and that of their children, including investments in child quality and lifetime savings in financial assets (Becker, 1981). These parents are typically assumed to have secure property rights to their savings and access to financial institutions that minimize credit constraints. Population policies that reduce the cost of avoiding unwanted births may also be expected to affect gender empowerment, which does not enter decisively in the unitary model of the family proposed by Becker, but emerges in various recent bargaining and collective models of the family. Women may differentially gain from improved control of reproduction, because they physically bear the health costs of having births and invest disproportionately their time in child rearing. To derive predictions on how family bargaining affects fertility or vice versa requires more context-specific assumptions. Do mothers or fathers value children more highly? Does improved birth control technology empower women to bargain for a larger share of the gains from marriage? These remain open questions for more study. Women may value children as much as men do, and use their own increases in wealth to have more. Increased unearned income owned 
by the wife is associated, if the husband's income is held constant, with higher fertility in Thailand but not in Brazil (Schultz, 1990). Microcredit targeted to groups of women in Bangladesh increases women's earnings and increases their later fertility (Pitt et al, 1999). In an experimentally designed family planning and health programme started in 1977 for women in rural villages of Matlab, Bangladesh, the women in villages benefiting from the programme had one fewer child by 1996 than did comparable women in comparison villages (Joshi and Schultz, 2007). The programme is also associated with increased woman's health, as measured by their body mass index (weight divided by height squared), reduced child mortality before age five, and increased years of schooling of boys aged 9-14 and 15-29. More studies of these long-run consequences of population policies on fertility and other family outcomes will be needed to assess the within-family consequences of fertility and population policies. Recognition that fertility is endogenous to other family life-cycle choices challenges economists to measure these potentially important life-cycle causal connections, and thereby provide a sounder basis for evaluating how population policies affects the social allocation of resources. 


\section{Bibliography}

Becker, G. S. 1960. An economic analysis of fertility. In Demographic and Economic Change in Developed Countries. Princeton, NJ: Princeton University Press and NBER.

Becker, G. S. 1981. A Treatise on the Family. Cambridge, MA: Harvard University Press.

Becker, G. S. and Lewis, H. G. 1974. Interactions between quantity and quality of children. In Economics of the Family, ed. T.W. Schultz. Chicago: University of Chicago Press.

Coale , A. C. 1973. The demographic transition reconsidered. Proceedings of the International Population Conference, vol. 1. Liège: International Union for the Scientific Study of Population.

Eckstein, Z., Schultz, T.P. and Wolpin, K. 1985. Short run fluctuations in fertility and mortality in pre-industrial Sweden. European Economic Review 26, 295-317.

Heckscher, E. F. 1963. An Economic History of Sweden, trans. G. Ohlin. Cambridge, MA: Harvard University Press.

Henry, L. 1972. On the Measurement of Human Fertility. Amsterdam: Elsevier.

Joshi, S. and Schultz, T. P. 2007. Family planning as a long term investment in development. Discussion paper 951, Economic Growth Center, Yale University.

Lee, R. 1981. Short term variation: vital rates, prices, and weather. In J.A. Wrigley and R. S. Schofield, The Population History of England, 1541-1871. Cambridge, MA: Harvard University Press.

Malthus, T.R. 1798. Essay on the Principle of Population, ed. A. Flew. Harmondsworth: Penguin, 1970. 
Mincer, J. 1963. Market prices, opportunity costs and income effects. In Measurement in Economics, ed. C. Christ et al. Stanford, CA: Stanford University Press.

National Research Council. 1986. Population Growth and Economic Development: Policy Questions. Washington, DC: National Academy Press.

Pitt, M., Khandkar, S. R., McKernan, S.-M. and Latif, M. A.1999. Credit programs for the poor and reproductive behavior in low income countries. Demography 35, 1-21.

Rose, E. 2000. Gender bias, credit constraint and time allocation in rural India. Economic Journal 110, 738-58.

Rosenzweig, M.R. and Wolpin, K. I. 1980. Testing the quantity-quality fertility model: the use of twins as a natural experiment. Econometrica 48, 227-40.

Rosenzweig, M.R. and Wolpin, K.I. 2000. Natural 'natural' experiments in economics. Journal of Economic Literature 38, 827-74.

Rosenzweig, M.R. and Zhang, J. 2006. Do population control policies induce more human capital investment? Twins, birthweight, and China’s ‘one child’ policy. Discussion Paper No. 933, Economic Growth Center, Yale University.

Schultz, T. P. 1981. Economics of Population. Reading, MA: Addison Wesley.

Schultz, T. P. 1985. Changing world prices, women's wages, and the fertility transition. Journal of Political Economy 93, 1126-54.

Schultz, T. P. 1990. Testing the neoclassical model of family labor supply and fertility. Journal of Human Resources 25, 559-634. 
Schultz, T. P. 2005. Population policies, fertility, women’s human capital and child quality. In Handbook of Development Economics, vol. 4, ed. T. P. Schultz, J. Strauss. Amsterdam: NorthHolland (forthcoming).

Smith, A. 1776. The Wealth of Nations, ed. E. Cannan. London: Methuen, 1961.

Willis, R.J. 1973. A new approach to the economic theory of fertility behavior. Journal of Political Economy 81(2, Part II), S14-S64.

Wrigley, J. A. and Schofield, R.S. 1981. The Population History of England, 1541-1871.

Cambridge, MA: Harvard University Press. 